\title{
Comunicación de la edad pulmonar para ayudar a los pacientes a dejar de fumar
}

\author{
Effect on smoking quit rates of telling patients their lung age
}

Parkes G y col. BMJ. 2008 Marzo 6; 336:598-600.

\section{Objetivo}

Evaluar la utilidad de informar a los fumadores su edad pulmonar, como herramienta para ayudarlos a dejar de fumar.

\section{Diseño, lugar y pacientes}

Ensayo clínico controlado aleatorizado, Hertfordshire, Inglaterra, con 561 fumadores mayores de 35 años con reporte en su historia clínica en los 12 meses previos al estudio.

\section{Intervención}

Se realizó una espirometría a todos los pacientes. A 280 se les informó su volumen espiratorio forzado en el primer segundo VEF1 a modo de "edad pulmonar" utilizando el gráfico de Fletcher y Peto (ver figura 1) y a 281 en litros/segundo. A ambos grupos se les explicó sobre los daños del tabaquismo y se les informó donde consultar para dejar de fumar. Luego de 12 meses se los volvió a citar para una nueva espirometría.

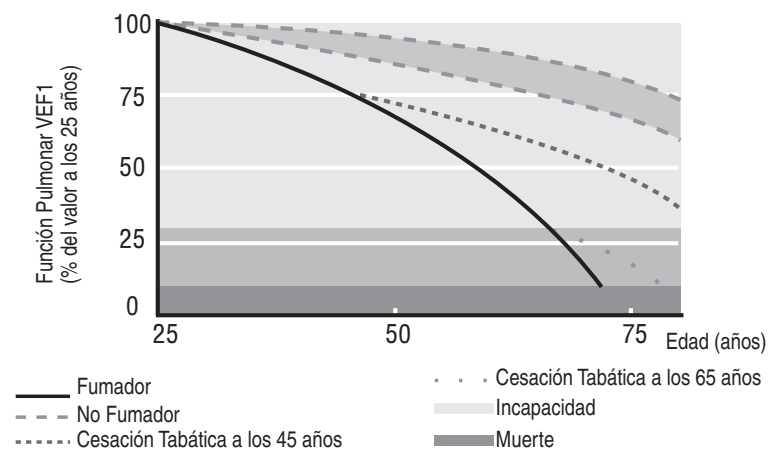

Modificado de: Fletcher C, Peto R. The natural history of chronic airflow obstruction. BMJ 1977;i:1645-8.

\begin{abstract}
Medición de resultados principales
Tasa de cesación tabáquica luego de 12 meses.
\end{abstract}

\section{Resultados Principales}

Existió un $11 \%$ de pérdidas en ambos grupos.

Decirle a los pacientes su edad pulmonar se asoció con una aumento absoluto del $7,2 \%$ en la tasa de cesación tabáquica. Ver tabla 1.

Tabla 1: comparación de las estrategias de informe de la espirometría respecto de la tasa de cesación tabáquica.

\begin{tabular}{c|c|c|c|c} 
& \multicolumn{2}{|c|}{ Modo de informe de la espirometria } & \multirow{2}{*}{$\begin{array}{c}\text { NNT } \\
\text { (IC95\%) }\end{array}$} \\
\cline { 2 - 3 } & $\begin{array}{c}\text { Litros por } \\
\text { segundo }(\mathbf{n}=281)\end{array}$ & $\begin{array}{c}\text { Edad pulmonar } \\
(\mathbf{n}=280)\end{array}$ & & 14 (8 a 45$)$ \\
\hline Cesación tabáquica & $(18) 6,4 \%$ & $(38) 13,6 \%$ & 0,01 & $14 \%$
\end{tabular}

NNT: número necesario de pacientes a los que este necesario contarle su edad pulmonar para lograr una cesación tabáquica adicional.

\section{Conclusiones}

Decirles a los pacientes tabaquistas su edad pulmonar y utilizar gráficos para explicarles el concepto, es útil para obtener una tasa de cesación tabáquica más alta.

Palabras claves: ensayo controlado aleatorizado, edad pulmonar, espirometría, tasa de cese tabáquico.

Key words: randomized controlled trial, lung age, spirometry, smoking quit rate. Fuente de financiamiento: Health Foundation.

\section{Comentario}

Un estudio cualitativo ${ }^{1}$ sobre cómo perciben los tabaquistas su enfermedad pulmonar, demostró que el cáncer de pulmón es el primer problema de salud que reconocen como consecuencia de su adicción, pero no mencionan la enfermedad pulmonar obstructiva crónica (EPOC).

Este estudio propone una estrategia novedosa y útil para fomentar la cesación tabáquica. Se puede afirmar que la intervención es exitosa, no siendo posible desglosar cuál es el componente de la misma que promueve el cambio, lo que sin embargo, no invalida sus resultados.

El uso de gráficos permite causar impacto visual y conseguir una mejor comprensión del daño progresivo que causa el tabaquismo sobre los pulmones. Permite explicar que en aquellos que sigan fumando habrá un deterioro progresivo, mientras que en los que abandonen el tabaquismo, el envejecimiento volverá a tener una velocidad similar a la del paciente no fumador. El concepto de edad pulmonar debe ser utilizado de forma tal, que el paciente perciba la posibilidad de mejorar su situación. Que sepa que si aún no hay daño pulmonar, está a tiempo de abandonar el tabaquismo y evitar el daño; y que si el deterioro ya es detectable, puede evitar el progreso del mismo.

\section{Conclusión de la comentadora}

Es eficaz utilizar el concepto de edad pulmonar para ayudar que los pacientes fumadores abandonen el tabaquismo, proponiéndose que este dato se incluya en forma rutinaria en los informes de la espirometría. Asimismo, sería de utilidad contar en el consultorio con un gráfico de Fletcher y Peto para explicarles a los pacientes el deterioro pulmonar causado por el tabaquismo y la posibilidad de detener su rápida progresión mediante su suspensión.

Tamara Sigal [ Servicio de Medicina Familiar y Comunitaria, Hospital Italiano de Buenos Aires. tamara.sigal@hospitalitaliano.org.ar ]

Sigal T. Comunicación de la edad pulmonar para ayudar a los paciente a dejar de fumar. Evid. actual. práct. ambul; 11(3):72 May-Jun.2008. Comentado de: Parkes G y col. Effect on smoking quit rate of telling patients their lung age: ths Step2quit randomised controlled trial. BMJ. 2008 Marzo 6; 336:598-600. PMID: 18326503. Disponible en URL: http://bmj.bmijournals.com/cgi/content/full/336/7644/598 (último acceso 03/06/08)

Referencia

1. Parker D y col. A qualitive Study of Individuals at Risk foro or Who Have Chronic Obstructive Pulmonary Disease: What Do They Understand About Their Disease?. Lung 2008. May 8

2. Todd C, Mclvor R, Pugsley S, Cox G. Approach to chronic obstructive pulmonary disease in primary care. Can Fam Physician. 2008 May 54;5:706-711 